\title{
Barleria prionitis Leaf Mediated Synthesis of Silver and Gold Nanocatalysts
}

Sougata Ghosh ${ }^{1 *}$, Maliyackal Jini Chacko', Ashwini N. Harke', Sonal P. Gurav¹, Komal A. Joshi², Aarti Dhepe ${ }^{2}$, Anuja S. Kulkarni ${ }^{3}$, Vaishali S. Shinde $^{3}$, Vijay Singh Parihar ${ }^{4}$, Adersh Asok ${ }^{5}$, Kaushik Banerjee ${ }^{6}$, Narayan Kamble ${ }^{6}$, Jayesh Bellare ${ }^{7}$ and Balu A. Chopade ${ }^{8}$

${ }^{1}$ Department of Microbiology, Modern College of Arts, Science and Commerce, Ganeshkhind, Pune-411016, India

${ }^{2}$ Institute of Bioinformatics and Biotechnology, University of Pune, Pune-411007, India

${ }^{3}$ Garware Research Centre, Department of Chemistry, University of Pune, Pune-411007, India

${ }^{4}$ New Chemistry Unit, Jawaharlal Nehru Centre for Advanced Scientific Research (JNCASR), Jakkur, Bengaluru-560064, India

${ }^{5}$ Materials Science and Technology Division, National Institute for Interdisciplinary Science and Technology, Council of Scientific and Industrial Research,

Thiruvananthapuram-695019, India

${ }^{6}$ National Referral Laboratory, ICAR-National Research Centre for Grapes, Manjri Farm, Pune-412307, India

${ }^{7}$ Department of Chemical Engineering, Indian Institute of Technology, Bombay, Powai, Mumbai-400076, India

${ }^{8}$ Dr Babasaheb Ambedkar Marathwada University, Aurangabad-431004, India

\begin{abstract}
Development of rapid, efficient, eco-friendly processes for synthesis of metal nanoparticles is one of the most significant thrust areas of nanobiotechnology. Medicinal plants are rich source of bioactive principles of diverse therapeutic importance. However, this unique phytochemistry can play a critical role not only in reduction of metal ions to their corresponding nanoparticles but also help to stabilize the same. Herein we report for the first time the synthesis of silver and gold nanoparticles using a medicinal plant, Barleria prionitis leaf extract. The synthesis was complete within $5 \mathrm{~h}$ and UV-vis spectra exhibited signature peaks at $420 \mathrm{~nm}$ and $540 \mathrm{~nm}$ for silver and gold nanoparticles, respectively. $3 \mathrm{mM} \mathrm{AgNO}$ and $2 \mathrm{mM} \mathrm{HAuCl}_{4}$ showed maximum synthesis of silver nanoparticles and gold nanoparticles, respectively at $50^{\circ} \mathrm{C}$. High resolution transmission electron microscopy revealed that majority of the silver nanoparticles was spherical in a size range between 10 to $20 \mathrm{~nm}$ while gold, between 10 to $25 \mathrm{~nm}$. Various exotic shapes were seen in case of gold nanoparticles like spheres, triangles and pentagons. The bioreduced nanoparticles were further characterized and confirmed using energy dispersive spectra, dynamic light scattering, X-ray diffraction spectrometry. Reducing sugars, ascorbic acid, starch, citric acid along with phenolics were found to be present in the extract that might play a major role in bioreduction and stabilization. GCMS/MS analysis further confirmed the diverse phytochemistry confirming tetradecane, 1-dodecanol, 3,7,11-trimethyl- and tert-hexadecanethiol as most predominant. Both silver and gold nanoparticles exhibited efficient catalytic reduction of $o$-nitrophenol.
\end{abstract}

Keywords: Barleria prionitis leaf extract; Gold nanoparticles; Silver nanoparticles; Gas chromatography mass spectrometry; catalysis

\section{Introduction}

Nanosized metal particles have got prime attention in past decades as their therapeutic properties are based on their size and shape. Thus fabrication, characterization and modification of their functional properties are critical for their applications in diagnostics and biomedical applications [1-3]. Nanomedicine bridges the gap between physics of the nanostructures and the biology behind their medicinal significance. Rationally designed nanomaterials have exhibited extensive applications in drug delivery, nanobiotechnology, targeted delivery, microfluidics, biosensors and microarrays to tissue micro-engineering $[4,5]$. Amongst diverse metal, organic, polymeric nanoparticles and liposomes, gold nanoparticles (AuNPs) and silver nanoparticles (AgNPs) have got wide applications in targeted, site-specific drug delivery thereby showing anticancer activity by eliminating tumorous outgrowth without any collateral damage [6]. Similarly, various efforts to design functionalized nanoparticles have helped in delivery of vaccines and anticancer drugs. Such nanomaterials serve the dual purpose as nano-carriers and enhancement of drug biodistribution. Spectacular success is achieved towards delivery of drugs through the blood brain barrier for targeting brain tumors. As more and more applications of nanomedicine in therapy are being explored, the need to develop more biocompatible nontoxic nanoparticles is gaining importance. Various biological methods for synthesis of nanoparticles using bacteria, fungi, algae are reported recently [7-14]. However, medicinal plants used in traditional, complementary and alternative therapy are considered as most promising biological route for synthesis of biocompatible metal nanoparticles. Recently we have reported nanobiotechnological applications about various medicinal plants like Gloriosa superba, Gnidia glauca, Dioscorea bulbifera, Plumbago zeylanica, Adiantum philippense L., Pterocarpus santalinus and Aloe vera [15-22].

Barleria prionitis, commonly known as Vajradanti is used for treating fever, respiratory diseases, toothache, joint pains, glandular swellings, boils, piles, ulcers and enlargement of scrotum $[23,24]$. Various parts of $B$. prionitis like leaf, stem, root, bark and flowers are utilized for treatment of catarrhal affections, whooping cough, inflammations, urinary infection, jaundice and gastrointestinal disorders. Diverse phytochemicals like balarenone, pipataline prionisides, barlerinoside, verbascoside, shanzhiside methyl ester, barlerin, acetylbarlerin, lupulinoside, scutellare, isolated from $B$. prionitis extracts exhibit antimicrobial, anthelmintic, antifertility, antioxidant, antidiabetic, antiinflammatory, anti-arthritic, cytoprotective, hepatoprotective, diuretic,

*Corresponding author: Sougata Ghosh, Department of Microbiology, Modern College of Arts, Science and Commerce, Ganeshkhind, Pune 411016, India, Tel: 9923268332; E-mail: ghoshsibb@gmail.com

Received August 10, 2016; Accepted August 19, 2016; Published August 26 , 2016

Citation: Ghosh S, Chacko MJ, Harke AN, Gurav SP, Joshi KA, et al. (2016) Barleria prionitis Leaf Mediated Synthesis of Silver and Gold Nanocatalysts. J Nanomed Nanotechnol 7: 394. doi: 10.4172/2157-7439.1000394

Copyright: @ 2016 Ghosh S, et al. This is an open-access article distributed unde the terms of the Creative Commons Attribution License, which permits unrestricted use, distribution, and reproduction in any medium, provided the original author and source are credited. 
antidiarrhoeal, enzyme inhibitory and anti-nociceptive activities without any toxic effects [25]. However, there are no detailed reports on its applications in nanobiotechnology.

In view of the background, it is of utmost scientific rationale to explore the potential of $B$. prionitis in nanotechnology. Thus, herein we report for the first time the detailed optimization and characterization studies of the AgNPs and AuNPs synthesized by B. prionitis (BPLE). Further, the bioreduced nanoparticles were checked for their chemocatalytic property.

\section{Materials and Methods}

\section{Plant material and preparation of extract}

B. prionitis leaves were collected from Western Ghats of Maharashtra, India which were dried in shade for 2-3 days at room temperature. The dried leaves were pulverised in an electric blender into fine powder. B. prionitis leaf extract (BPLE) was prepared by boiling $5 \mathrm{~g}$ of leaf powder in $100 \mathrm{~mL}$ distilled water for $5 \mathrm{~min}$. After decantation the extract was centrifuged at $3000 \mathrm{rpm}$ for $10 \mathrm{~min}$ and filtered through Whatman No.1 filter paper. The filtrate was collected and stored at $4^{\circ} \mathrm{C}$ for further use [18].

\section{Synthesis and characterization of silver and gold nanopar- ticles}

In $95 \mathrm{~mL}$ of $1 \mathrm{mM} \mathrm{AgNO}_{3}$ solution $5 \mathrm{~mL}$ of BPLE was added to initiate the synthesis of AgNPs. The reaction mixture was shaken at $40^{\circ} \mathrm{C}$ for $5 \mathrm{~h}$ in a shaker incubator. Reduction of $\mathrm{Ag}^{+}$ions to AgNPs was confirmed by visible colour change and by using UV-visible spectrometry at regular intervals. Similarly, synthesis of AuNPs was achieved by addition of $5 \mathrm{~mL}$ of BPLE into $95 \mathrm{~mL}$ of $1 \mathrm{mM} \mathrm{HAuCl}_{4}$ solution. Temperature optimization was carried out in a water bath at $4^{\circ} \mathrm{C}-50^{\circ} \mathrm{C}$ with reflux. Concentration optimization was performed by varying the respective salt concentration from 0.3 to $5 \mathrm{mM}$. Characterization of the bioreduced nanoparticles was carried out employing high resolution transmission electron microscopy (HRTEM), energy dispersive spectroscopy (EDS), $\mathrm{X}$-ray diffraction (XRD) and fourier transform infrared spectroscopy (FTIR) as per our earlier reports [18].

\section{Phytochemicals analysis}

Various components in BPLE such as total phenolic, flavonoid, starch, reducing sugar, ascorbic acid and citric acid were estimated using biochemical assays reported earlier [Ghosh IJN, 2012]. Similarly, identification of the principle phytochemicals was carried out using GC-MS/MS analysis [26].

\section{Catalytic activity}

A standard catalytic test reaction was carried out in $4.5 \mathrm{~mL}$ quartz cuvettes. Aqueous solution of $0.1 \mathrm{mM} o$-nitrophenol $(2 \mathrm{~mL})$ was mixed with $1 \mathrm{~mL}$ of $0.1 \mathrm{M}$ sodium borohydride solution. The reaction was started by addition of $15 \mu \mathrm{L}$ of $10 \mathrm{mM}$ AuNPs and AgNPs separately. Immediately after catalyst addition, time dependent absorption spectra were collected at $5 \mathrm{~min}$ intervals for $30 \mathrm{~min}$ at room temperature in the range of 250-550 $\mathrm{nm}$. The background subtraction was done using deionized water as the reference [20].

\section{Results}

\section{UV-visible spectroscopy}

Colour of the $\mathrm{AgNO}_{3}$ aqueous solution turned to light brown initially after $1 \mathrm{~h}$ on addition of BPLE which gradually developed into intense brown confirming the synthesis of AgNPs. UV-visible spectra taken at regular intervals further showed a gradual development of peak at $420 \mathrm{~nm}$ from 0 to $5 \mathrm{~h}$ (Figure 1A). Similarly, faint yellow colour of $\mathrm{HAuCl}_{4}$ solution initially turned into purple and finally changed into intense ruby red colour indicating the synthesis of AuNPs on addition of BPLE. Although at $0 \mathrm{~h}$ and $0.5 \mathrm{~h}$ no significant peak was observed in UV-visible spectra, from $1 \mathrm{~h}$ onwards a peak was observed at $540 \mathrm{~nm}$ which sharply increased in $2 \mathrm{~h}$ (Figure 1B). With further incubation, the peak at the same wavelength increased till $5 \mathrm{~h}$. Optimization studies revealed that higher temperature facilitated the synthesis of both AgNPs and AuNPs (Figure 2A and 2B). Least reduction was achieved with $4^{\circ} \mathrm{C}$, while maximum bioreduction by BPLE was observed at a higher temperature of $50^{\circ} \mathrm{C}$. Concentration optimization studies showed that for AgNPs synthesis the concentration of $\mathrm{AgNO}_{3}$ played a critical role. Higher salt concentration showed greater bioreduction of AgNPs as observed by recording absorbance at $420 \mathrm{~nm}$. Although till $2 \mathrm{~h}$, much significant difference was not observed, from $3 \mathrm{~h}$ onwards $4 \mathrm{mM}$ and $5 \mathrm{mM}$ showed higher rate of AgNPs synthesis. However, between 4 $\mathrm{h}$ to $5 \mathrm{~h}, 3 \mathrm{mM} \mathrm{AgNO}$ showed maximum synthesis (Figure $3 \mathrm{~A}$ ). In case of AuNPs higher rate of synthesis was achieved by increasing the concentration till $2 \mathrm{mM} \mathrm{HAuCl}_{4}$ (Figure 3B). Thereafter, on increasing the salt concentration, a drop in the rate of synthesis was observed.

\section{HRTEM, EDS and DLS analysis}

Majority of the AgNPs synthesized by BPLE were found to be
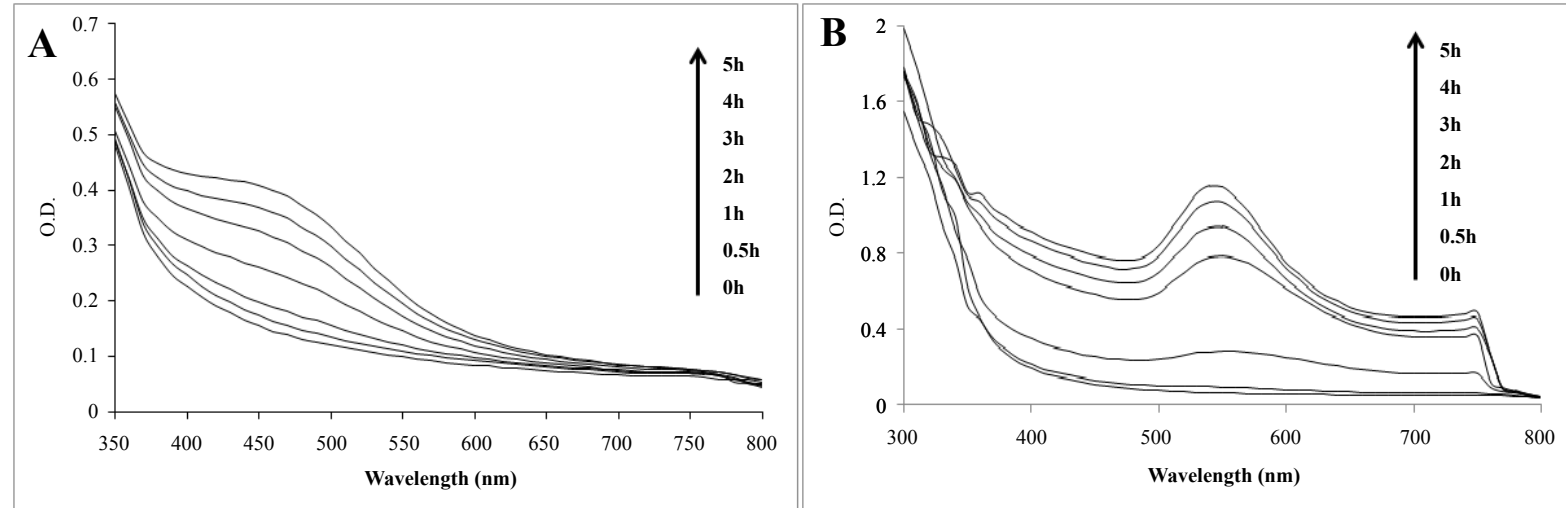

Figure 1: UV-vis spectra recorded as a function of reaction time for nanoparticle formation using BPLE at $40^{\circ} \mathrm{C}$ with (A) $1 \mathrm{mM} \mathrm{AgNO}_{3}$ solution and (B) $\mathrm{HAuCl}_{4}$ solution. 
Citation: Ghosh S, Chacko MJ, Harke AN, Gurav SP, Joshi KA, et al. (2016) Barleria prionitis Leaf Mediated Synthesis of Silver and Gold Nanocatalysts. J Nanomed Nanotechnol 7: 394. doi: 10.4172/2157-7439.1000394
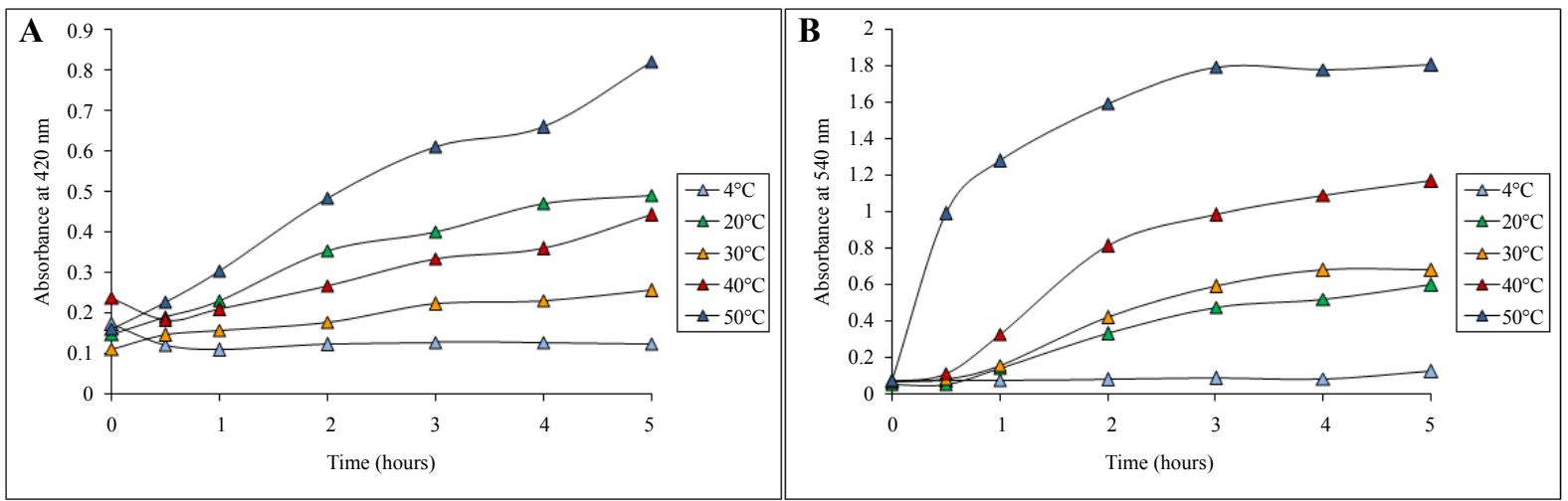

Figure 2: Time course of nanoparticle synthesis using BPLE at different reaction temperatures with (A) $1 \mathrm{mM} \mathrm{AgNO}_{3}$ and $(\mathrm{B}) 1 \mathrm{mM} \mathrm{HAuCl}{ }_{4}$.
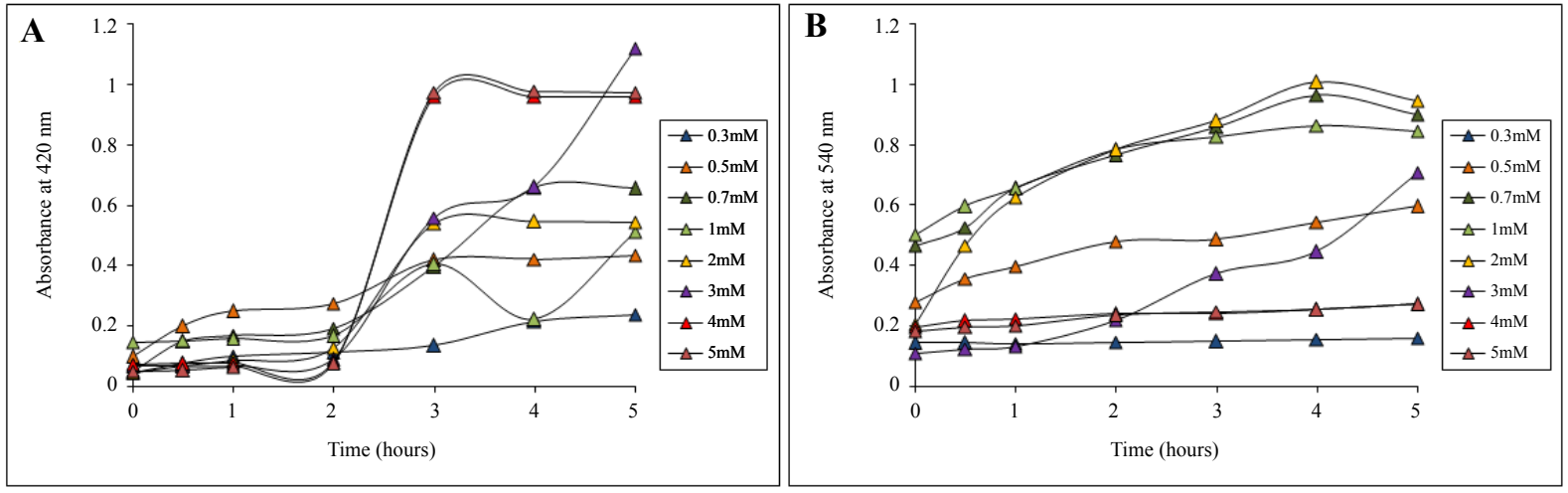

Figure 3: Time course of nanoparticle synthesis using BPLE at $40{ }^{\circ} \mathrm{C}$ with (A) different concentrations of $\mathrm{AgNO}_{3}$ and (B) $\mathrm{HAuCl}_{4}$.

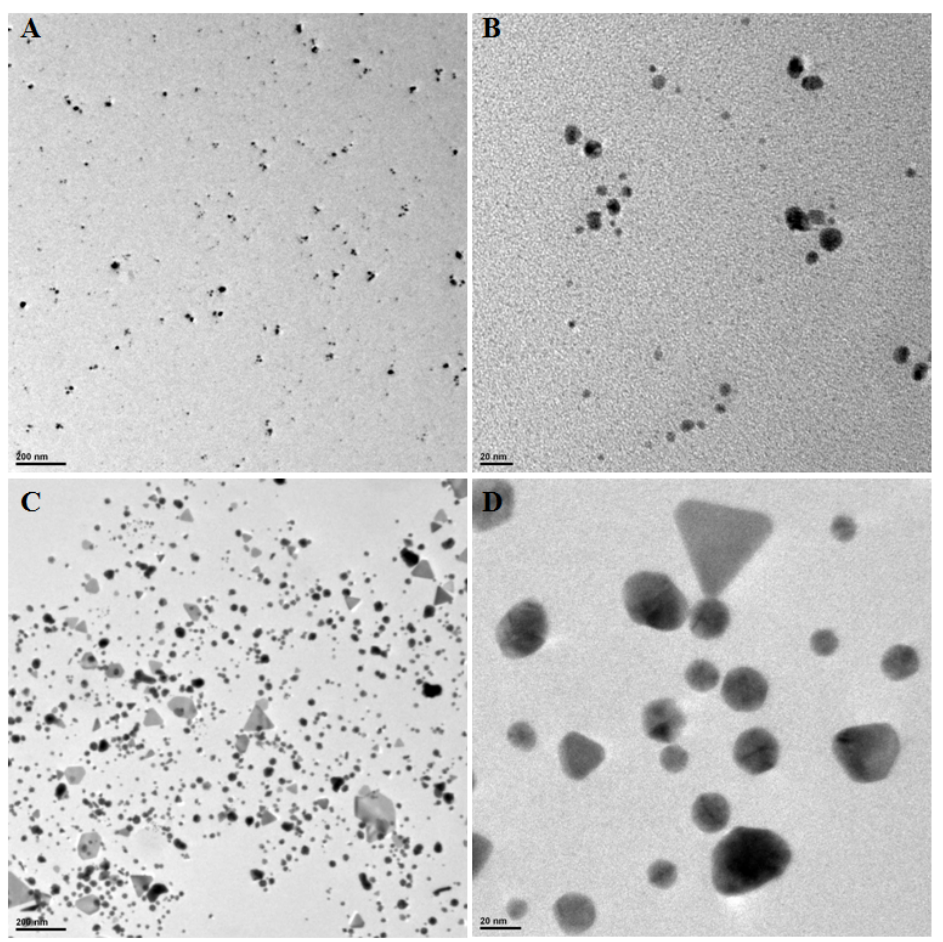

Figure 4: High-resolution transmission electron micrographs of nanoparticles synthesized by BPLE. (A) AgNPs bioreduced by BPLE, inset bar representing of $200 \mathrm{~nm}$; (B) Magnified image of very small spherical AgNPs bioreduced by BPLE, inset bar representing of $20 \mathrm{~nm}$; (C) AuNPs synthesized by BPLE, inset bar representing of $200 \mathrm{~nm}$; (D) Magnified truncated nano-triangles, pentagons and spheres synthesized by BPLE, inset bar representing of $20 \mathrm{~nm}$. 
Citation: Ghosh S, Chacko MJ, Harke AN, Gurav SP, Joshi KA, et al. (2016) Barleria prionitis Leaf Mediated Synthesis of Silver and Gold Nanocatalysts. J Nanomed Nanotechnol 7: 394. doi: 10.4172/2157-7439.1000394

Page 4 of 7

spherical ranging from 10 to $20 \mathrm{~nm}$ (Figure $4 \mathrm{~A}$ ). Particles were fairly dispersed and rarely found to be in agglomeration. Smaller AgNPs combined to form particles with larger dimensions which were oval in shape (Figure 4B). AuNPs showed anisotropy where although spherical particles were major, particles of other exotic shapes were also visualized. Most of the AuNPs synthesized by BPLE were found to be spherical ranging from $10 \mathrm{~nm}$ to $25 \mathrm{~nm}$ (Figure 4C). Particles were free and agglomeration was not observed. Blunt ended nanopentagons were also seen along with nanotriangles (Figure 4D). EDS analysis exhibiting the signature peaks for elemental Ag and $\mathrm{Au}$ in the bioreduced nanoparticles confirmed the synthesis of AgNPs and AuNPs, respectively by BPLE (Figure 5A and 5B). Size distribution of bioreduced nanoparticles observed in DLS was also found to be in close agreement with the HRTEM results (Figure 6A and 6B).

\section{XRD analysis}

The Figure 7A shows the diffraction peaks of AgNPs synthesized using BPLE as a reducing agent, which shows the characteristic diffraction peaks at (111), (200), (220), and (311) usually observed for face-centered cubic silver crystals (JCPDS card No. 04-0783). Similarly, the crystal phase of AgNPs and AuNPs, bioreduced by BPLE was confirmed using XRD, as shown in the Figure 7B. The observed characteristic diffraction peaks at (111), (200), (220), and (311) matches well with JCPDS card No. 04-0784, confirming the cubic phase of AuNPs. A broadening of the diffraction peaks can be observed for Figure 7A and 7B, possibly due to surface strain and reduced particle size as observed in the HRTEM images.

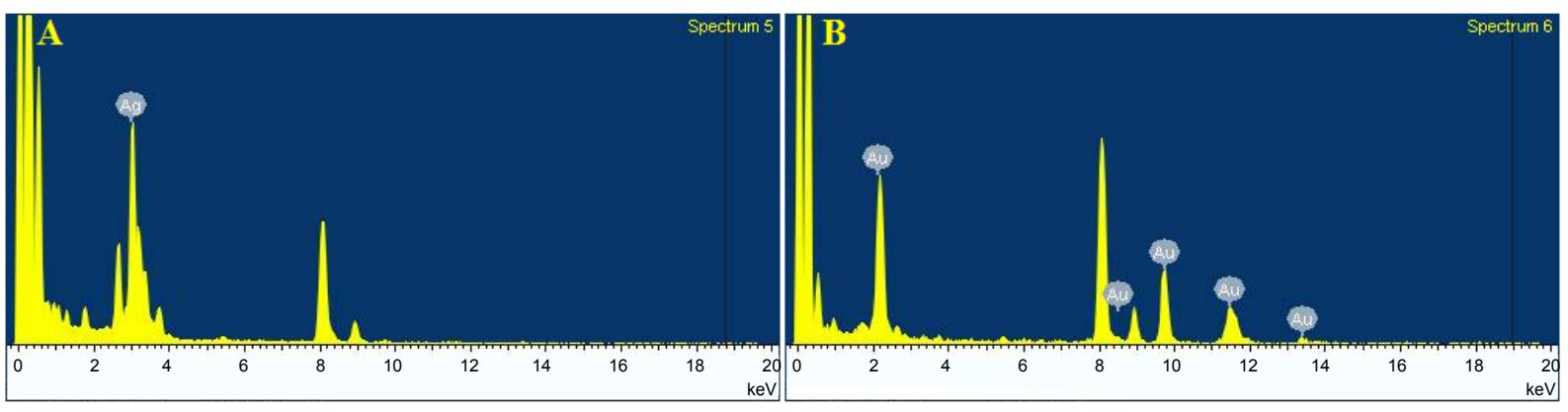

Figure 5: Representative spot EDS profile of (A) AgNPs and (B) AuNPs bioreduced by BPLE.
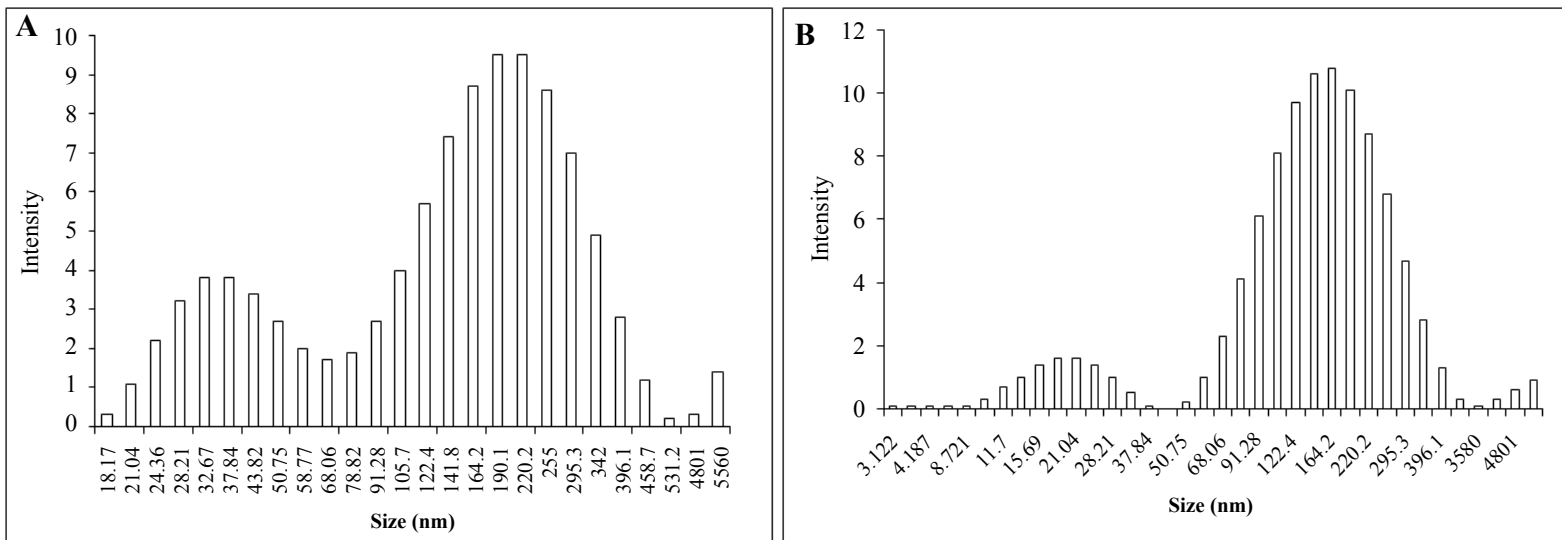

Figure 6: Histogram of size distribution of nanoparticles synthesized by BPLE. (A) AgNPs and (B) AuNPs.
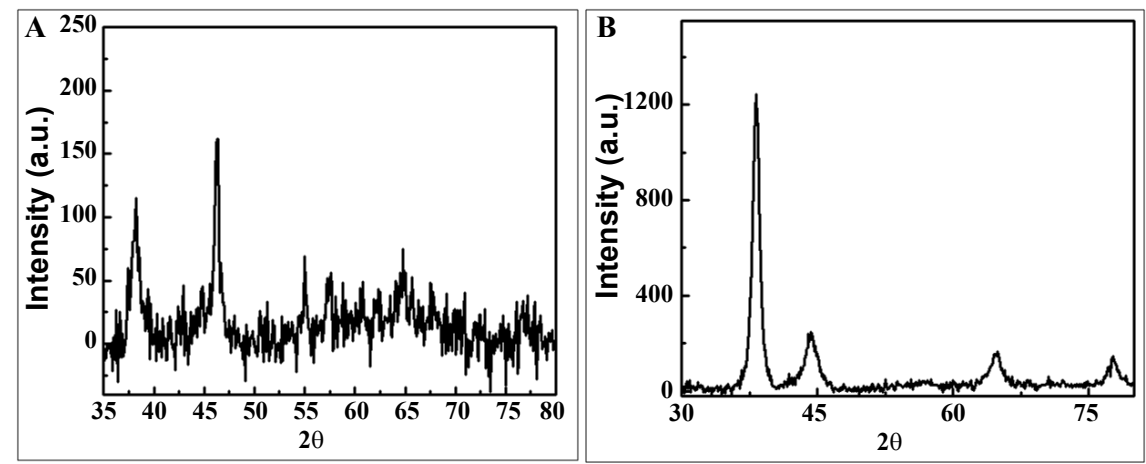

Figure 7: Representative X-ray diffraction profile of thin film AgNPs (A) and AuNPs (B) synthesized by BPLE. 
Citation: Ghosh S, Chacko MJ, Harke AN, Gurav SP, Joshi KA, et al. (2016) Barleria prionitis Leaf Mediated Synthesis of Silver and Gold Nanocatalysts. J Nanomed Nanotechnol 7: 394. doi: 10.4172/2157-7439.1000394

Page 5 of 7

\section{FTIR analysis}

The bending vibrations associated to amine $(\mathrm{N}-\mathrm{H})$ can be observed in the FTIR for BPLE before reduction (Figure $8 \mathrm{~A}$ ) as well as after synthesis of AgNPs (Figure 8B) and AuNPs (Figure 8C). However, the BPLE showed a shift of peaks to lower wavenumber $\left(1631.61 \mathrm{~cm}^{-1} \rightarrow\right.$ $1579.63 \mathrm{~cm}^{-1}$ ) region. An increase in the transmittance was observed for bending vibrations related to alkane at $1397.71 \mathrm{~cm}^{-1}$ after bioreduction of AgNPs and AuNPs. Similarly, vibrational stretching of ether group (C-O) also showed the same trend of increase in the transmittance after bioreducton. Additional vibration associated with alkene $(=\mathrm{C}-\mathrm{H})$ was also observed after synthesis of AgNPs and AuNPs which could be attributed due to the bond formation with the organic moieties of BPLE, thereby giving it stability.

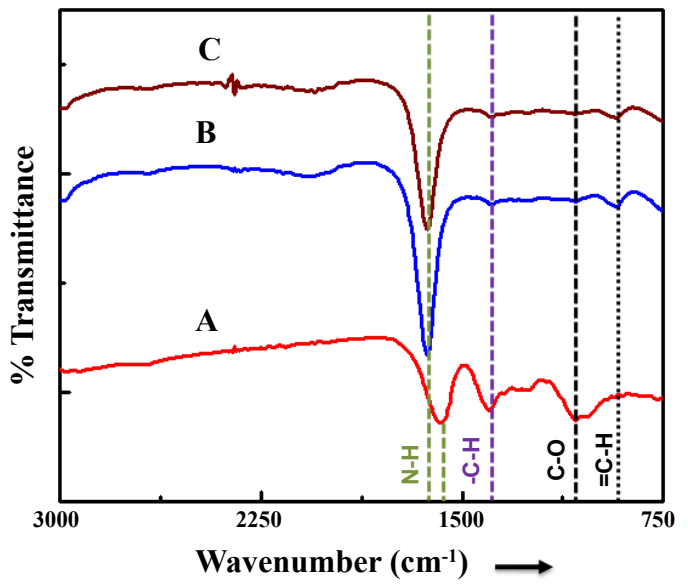

Figure 8: Fourier transform infrared absorption spectra of BPLE before bioreduction (A) and after complete bioreduction of AgNPs (B) and AuNPs (C).

\section{Phytochemical analysis}

Various phytochemicals were observed to be present in BPLE, major being reducing sugars. Presence of high amount of ascorbic acid was also observed followed by starch (Table 1). BPLE showed presence of phenolics and citric acid as well. GCMS/MS analysis confirmed the diverse phytochemistry of BPLE as well, the predominant being, tetradecane, 1-dodecanol, 3,7,11-trimethyl- and tert-hexadecanethiol.

\section{Catalytic activity}

The catalytic model reaction of $o$-nitrophenol to $o$-aminophenol by sodium borohydride with AgNPs and AuNPs was investigated using UV-Vis spectroscopy. Clear solution of $o$-nitrophenol turns pale yellow upon adding sodium borohydride. After the addition of gold nanoparticles, the pale yellow colour slowly changes to colourless solution indicating conversion of nitro-group to amine group. As shown in Figure 9A and 9B, during time intervals of 5 to $30 \mathrm{~min}$, the intensity of the characteristic absorption band of $o$-nitrophenol at 400 $\mathrm{nm}$ disappeared, whereas a new peak at $290 \mathrm{~nm}$ (due to $o$-aminophenol) appeared. This demonstrated the capability of the bioreduced AgNPs and AuNPs to act as biocompatible chemocatalysts. However, in case of AgNPs no conversion was observed after 10 min (Table 2).

\section{Discussion}

The present study demonstrated a rapid, efficient and environmentally benign route for synthesis of AgNPs and AuNPs using medicinally important plant $B$. prionitis. UV-visible spectrum showing a characteristic absorption peak at $420 \mathrm{~nm}$ that further confirmed the formation of AgNPs which corresponds to surface plasmon resonance of AgNPs as reported earlier using Acalypha indica leaf extract [27]. UV-visible spectra of AuNPs synthesized using BPLE with surface plasmon resonance band around $540 \mathrm{~nm}$ was found to be in close

\begin{tabular}{|c|c|c|c|c|c|}
\hline \multirow{2}{*}{ Sample } & \multicolumn{4}{|c|}{ Phytochemicals $(\boldsymbol{\mu g} / \mathbf{m L})$} \\
\cline { 2 - 6 } & Phenolic content & Starch content & Reducing sugars & Ascorbic acid & Citric acid \\
\hline BPLE & 7.77 & 55.44 & 384.40 & 100 & 10.03 \\
\hline
\end{tabular}

Table 1: Phytochemical composition of BPLE.

\begin{tabular}{|c|c|c|c|c|}
\hline Sr. No & Name of compounds & RTS & Formula & Molecular weight \\
\hline 1 & 1-Octen-3-ol & 8.7 & $\mathrm{C}_{8} \mathrm{H}_{16} \mathrm{O}$ & 128 \\
\hline 2 & Decane, 2,3,5,8-tetramethyl- & 9.55 & $\mathrm{C}_{14} \mathrm{H}_{30}$ & 198 \\
\hline 3 & 2-Undecanethiol, 2-methyl- & 11.83 & $\mathrm{C}_{12} \mathrm{H}_{26} \mathrm{~S}$ & 202 \\
\hline 4 & Heptadecane, 2,6,10,15-tetramethyl- & 16.26 & $\mathrm{C}_{12} \mathrm{H}_{44}$ & 296 \\
\hline 5 & Tetradecane, 2,6,10-trimethyl- & 17.65 & $\mathrm{C}_{17} \mathrm{H}_{36}$ & 240 \\
\hline 6 & 2-Isopropyl-5-methyl-1-heptanol & 19.72 & $\mathrm{C}_{11} \mathrm{H}_{24} \mathrm{O}$ & 172 \\
\hline 7 & Hexadecane, 1,1-bis(dodecyloxy)- & 22.78 & $\mathrm{C}_{40} \mathrm{H}_{82} \mathrm{O}_{2}$ & 594 \\
\hline 8 & Tetradecane & 23.04 & $\mathrm{C}_{14} \mathrm{H}_{30}$ & 198 \\
\hline 9 & Disulfide, di-tert-dodecyl & 25 & $\mathrm{C}_{24} \mathrm{H}_{50} \mathrm{~S}_{2}$ & 402 \\
\hline 10 & 1-Hexadecanol, 2-methyl- & 25.61 & $\mathrm{C}_{17} \mathrm{H}_{36} \mathrm{O}$ & 256 \\
\hline 11 & Phenol, 2,4-bis(1,1-dimethylethyl)- & 26.56 & $\mathrm{C}_{14} \mathrm{H}_{22} \mathrm{O}$ & 206 \\
\hline 12 & 1-Dodecanol, 3,7,11-trimethyl- & 26.88 & $\mathrm{C}_{15} \mathrm{H}_{32} \mathrm{O}$ & 228 \\
\hline 13 & tert-Hexadecanethiol & 27.11 & $\mathrm{C}_{16} \mathrm{H}_{34} \mathrm{~S}$ & 258 \\
\hline 14 & cis-1-Chloro-9-octadecene & 28.88 & $\mathrm{C}_{18} \mathrm{H}_{35} \mathrm{Cl}$ & 286 \\
\hline 15 & 3-Chloropropionic acid, heptadecyl ester & 31.69 & $\mathrm{C}_{20} \mathrm{H}_{39} \mathrm{ClO}_{2}$ & 346 \\
\hline 16 & 2-Hexadecanol & 34.38 & $\mathrm{C}_{16} \mathrm{H}_{34} \mathrm{O}$ & 242 \\
\hline 17 & Heptacosane & 34.56 & $\mathrm{C}_{27} \mathrm{H}_{56}$ & 380 \\
\hline 18 & 17-Pentatriacontene & 35.5 & $\mathrm{C}_{35} \mathrm{H}_{70}$ & 490 \\
\hline 19 & 2-Pentadecanone, 6,10,14-trimethyl- & 35.61 & $\mathrm{C}_{18} \mathrm{H}_{36} \mathrm{O}$ & 268 \\
\hline
\end{tabular}

Table 2: Main compounds detected by GCMS/MS. 

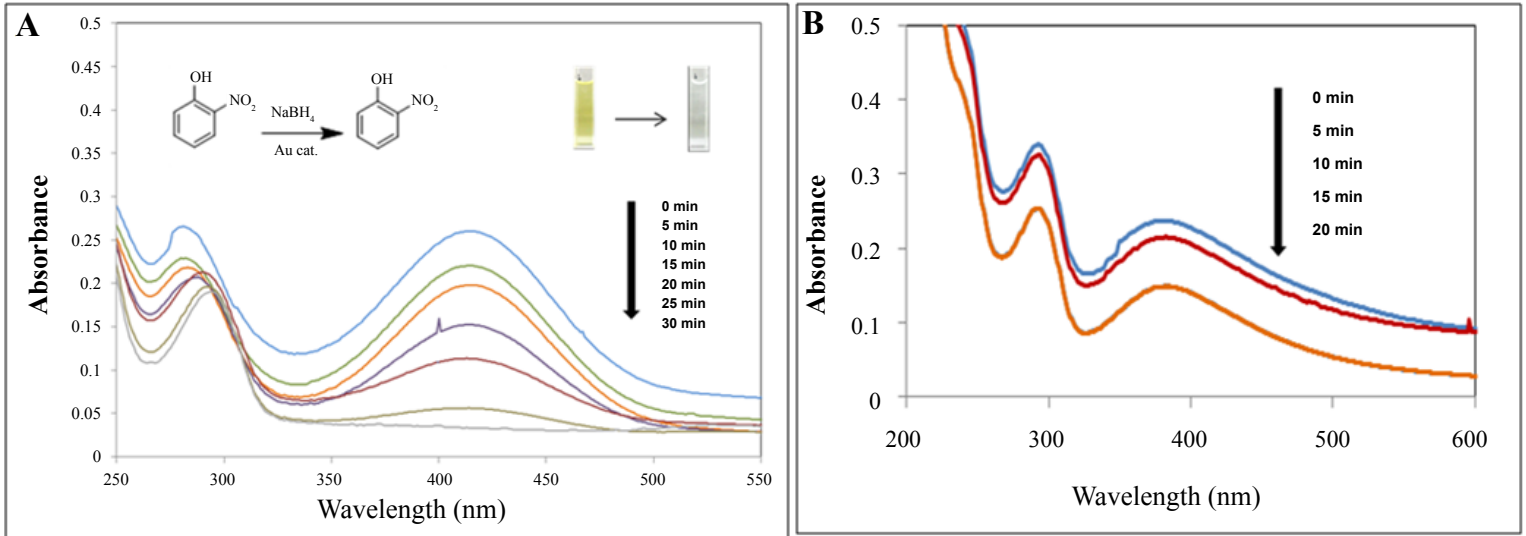

Figure 9: Catalytic reduction of o-nitrophenol in the presence of AuNPs (A) and AgNPs (B) synthesized by BPLE.

agreement with previous report on synthesis of AuNPs using flower extract of Achillea wilhelmsii [28]. Development of red color was due to the excitation of surface plasmon vibrations in the AuNPs which is absent in bulk metallic gold [29]. The synthesis was completed within $5 \mathrm{~h}$ which was found to be rapid compared to other plants like Aloe vera which took $24 \mathrm{~h}$ for complete reduction [30]. Optimization studies indicated that both reaction temperature and metal salt concentrations play a major role in the rate of bioreduction which was similar to earlier reports on Plumbago zeylanica [22]. AgNPs synthesized by BPLE were mostly found to be spherical in shape which was even reported in case of AgNPs synthesized by Azadirachta indica (Neem) leaves [31]. AuNPs were found to be of exotic shapes and of varied sizes which was found as well in case of synthesis using other medicinal plants like D. bulbifera [19]. Phytochemical diversity of BPLE included phenolics, reducing sugars, ascorbic acid, citric acid along with many others as evident from GCMS/MS analysis that might play a critical role in both reduction and stabilization of the nanoparticles [32]. AuNPs synthesized by BPLE were found to have efficient catalytic activity as compared to AgNPs. Slow rate of catalytic activity AgNPs might be attributed to their relative larger size and the formation of surface oxide layer as reported in case of Breynia rhamnoides [33]. Our results are in close agreement with the earlier reports on AuNPs synthesized from medicinal plants like Gnidia glauca and Acacia nilotica [1,20,34-36].

\section{Conclusion}

A rapid, efficient and environmentally benign synthesis of AgNPs and AuNPs is demonstrated using B. prionitis leaf which is considered as a very significant complementary and alternative medicine against various ailments. Rate of synthesis was found to be a function of time, temperature and concentrations of the salt solution. Diverse groups of phytochemicals like polyphenols, starch, reducing sugars, ascorbic acid and citric acid play critical role in both bioreduction and stabilization of AgNPs and AuNPs that were found to be in a size range between 10 to $25 \mathrm{~nm}$. Exotic shapes of AuNPs were observed. The bioreduced AuNPs and AgNPs show chemocatalytic potential in conversion of $o$-nitrophenol to $o$-aminophenol.

\section{Acknowledgment}

The authors acknowledge the help extended for the use of TEM and HRTEM facilities in Chemical Engineering and CRNTS funded by the DST through Nanomission and IRPHA schemes.

\section{References}

1. Ghosh S, Patil S, Chopade NB, Luikham S, Kitture R, et al. (2016) Gnidia glauca leaf and stem extract mediated synthesis of gold nanocatalysts with free radical scavenging potential. J Nanomed Nanotechno 7: 2 .

2. Ghosh S, More P, Nitnavare R, Jagtap S, Chippalkatti R, et al. (2015) Antidiabetic and antioxidant properties of copper nanoparticles synthesized by medicinal plant Dioscorea bulbifera. J Nanomed Nanotechnol S6: 007.

3. Asok A, Kulkarni AR, Ghosh S, More P, Chopade BA, et al. (2015) Surface defect rich $\mathrm{ZnO}$ quantum dots as antioxidant inhibiting a-amylase and $\alpha$-glucosidase: A potential anti-diabetic nanomedicine. J Mater Chem B 3: 4597-4606.

4. Kitture R, Ghosh S, More PA, Date K, Gaware S, et al. (2015) Curcuminloaded, self-assembled Aloe vera template for superior antioxidant activity and trans-membrane drug release. J Nanosci Nanotechnol 15: 4039-4045.

5. Kitture R, Chordiya K, Gaware S, Ghosh S, More PA, et al. (2015) ZnO nanoparticles-red sandalwood conjugate: A promising anti-diabetic agent. J Nanosci Nanotechnol 15: 4046-4051.

6. Kitture R, Ghosh S, Kulkarni P, Liu XL, Maity D, et al. (2012) Fe $\mathrm{O}_{4}$-citrate curcumin: Promising conjugates for superoxide scavenging, tumor suppression and cancer hyperthermia. J Appl Phys 111: 064702.

7. Singh R, Shedbalkar UU, Wadhwani SA, Chopade BA (2015) Bacteriagenic silver nanoparticles: synthesis, mechanism, and applications. Appl Microbiol Biotechnol 99: 4579-4593.

8. Wadhwani SA, Shedbalkar UU, Singh R, Chopade BA(2016) Biogenic selenium nanoparticles: current status and future prospects. Appl Microbiol Biotechnol.

9. Singh R, Nawale LU, Arkile M, Shedbalkar UU, Wadhwani SA, et al. (2015) Chemical and biological metal nanoparticles as antimycobacterial agents: A comparative study. Int J Antimicrob Agents 46: 183-8.

10. Deshpande P, Gaidhani S, Hitendra M, Shouche Y, Chopade BA, et al. (2015) Biosynthesis of gold nanoparticles by human microbiota from healthy skins. J Nanomed Nanotechnol 6: 4 .

11. Gaidhani SV, Yeshvekar RK, Shedbalkar UU, Bellare JH, Chopade BA (2014) Bio-reduction of hexachloroplatinic acid to platinum nanoparticles employing Acinetobacter calcoaceticus. Process Biochem 49: 2313-2319.

12. Wadhwani SA, Shedbalkar UU, Singh R, Karve MS, Chopade BA (2014) Novel polyhedral gold nanoparticles: green synthesis, optimization and characterization by environmental isolate of Acinetobacter sp. SW30. World J Microb Biotechnol 30: 2723-2731.

13. Gaidhani S, Singh R, Singh D, Patel U, Chopade BA, et al. (2013) Biofilm disruption activity of silver nanoparticles synthesized by Acinetobacter calcoaceticus PUCM 1005. Mater Lett 108: 324-327.

14. Singh R, Wagh P, Wadhwani S, Brllare J, Chopade BA, et al. (2013) Synthesis, optimization, and characterization of silver nanoparticles from Acinetobacter calcoaceticus and their enhanced antibacterial activity when combined with antibiotics. Int J Nanomed 8: 4277-4290.

15. Ghosh S, Harke AN, Chacko MJ, Gurav SP, Joshi KA, et al. (2016) Gloriosa 
Citation: Ghosh S, Chacko MJ, Harke AN, Gurav SP, Joshi KA, et al. (2016) Barleria prionitis Leaf Mediated Synthesis of Silver and Gold Nanocatalysts. J Nanomed Nanotechnol 7: 394. doi: 10.4172/2157-7439.1000394

superba mediated synthesis of silver and gold nanoparticles for anticancer applications. J Nanomed Nanotechnol 7: 4

16. Ghosh S, Nitnavare R, Dewle A, Tomar GB, Chippalkatti R, et al. (2015) Novel platinum-palladium bimetallic nanoparticles synthesized by Dioscorea bulbifera: anticancer and antioxidant activities. Int J Nanomed 10: 1- 4

17. Ghosh S, Jagtap S, More P, Shete UJ, Maheshwari NO, et al. (2015) Dioscorea bulbifera mediated synthesis of novel $\mathrm{Au} \mathrm{Ag}_{\text {nen }}$ nanoparticles with potent antibiofilm and antileishmanial activity. J Nanomater.

18. Ghosh S, Patil S, Ahire M, Kitture R, Kale S, et al. (2012) Synthesis of silver nanoparticles using Dioscorea bulbifera tuber extract and evaluation of its synergistic potential in combination with antimicrobial agents. Int J Nanomedicine 7: 483-496.

19. Ghosh S, Patil S, Ahire M, Kitture R, Jabgunde A, et al. (2011) Synthesis of gold nanoanisotrops using Dioscorea bulbifera tuber extract. J Nanomater 2011: 354793

20. Ghosh S, Patil S, Ahire M, Kitture R, Gurav DD, et al. (2012) Gnidia glauca flower extract mediated synthesis of gold nanoparticles and evaluation of its chemocatalytic potential. J Nanobiotechnol 10: 17

21. Ghosh S, More P, Derle A, Kitture R, Kale T, et al. (2015) Diosgenin functionalized iron oxide nanoparticles as novel nanomaterial against breast cancer. J Nanosci Nanotechnol 15: 1-9.

22. Salunke R, Ghosh S, Kumar RJS, Khade S, Vashisth P, et al. (2014) Rapid efficient synthesis and characterization od AgNPs, AuNPs and AgAuNPs from a medicinal plant, Plumbago zeylanica and their application in biofilm control. Int J Nanomedicine 9: 2635-2653.

23. Diwan PD, Gadhikar YA (2012) Assessment of phytochemical composition and antibacterial activity of different extracts of Barleria prionitis leaves against oral microflora to improve dental hygiene. Asian J Pharm Clin Res 5: 182-184.

24. Chavan C, Mulik S, Maheshwari C, Adnaik R, Patil P (2011) Screening of antioxidant activity and phenolic content of whole plant of Barleria prionitis Linn. Int J Res Ayurveda Pharmacy 2: 1313-1319.

25. Banerjee D, Maji AK, Mahapatra S, Banerji P (2012) Barleria prionitis Linn: A review of its traditional uses, phytochemistry, pharmacology and toxicityresearch. J Phytochem 6: 31-41.

26. Ghosh S, More P, Derle A, et al. (2014) Diosgenin from Dioscorea bulbifera:
Novel hit for treatment of Type II Diabetes Mellitus with inhibitory activity against a-amylase and $\alpha$-glucosidase. PLoS ONE 9: e106039.

27. Krishnaraj C, Ramachandran R, Mohan K, Kalaichelvan PT (2012) Optimization for rapid synthesis of silver nanoparticles and its effect on phytopathogenic fungi. Spectrochim Acta 93: 95- 99.

28. Andeani JK, Kazemi H, Mohsenzadeh S, Safavi A (2011) Biosynthesis of gold nanoparticles using dried flowers extract of Achillea wilhelmsii plant. Digest $J$ Nanomater Biostructures 6: 1011-1017.

29. Sheny DS, Mathew J, Philip D (2011) Phytosynthesis of Au, Ag and Au-Ag bimetallic nanoparticles using aqueous extract and dried leaf of Anacardium occidentale. Spectrochim Acta A 79: 254-262.

30. Chandran SP, Chaudhary M, Pasricha R, Ahmad A, Sastry M (2006) Synthesis of gold nanotriangles and silver nanoparticles using Aloe vera plant extract. Biotechnol Prog 22: 577-583.

31. Tripathy A, Raichur AM, Chandrasekaran N, Prathna TC, Mukherjee A (2010) Process variables in biomimetic synthesis of silver nanoparticles by aqueous extract of Azadirachta indica (Neem) leaves. J Nanopart Res 12: 237-246.

32. Zhang W, Qiao X, Chena J (2007) Synthesis of silver nanoparticles-Effects of concerned parameters in water/oil microemulsion. Mater Sci Engineer B 142: 1-15.

33. Gangula A, Podila R, Ramakrishna M, Karanam L, Janardhana C, et al. (2011) Catalytic reduction of 4-nitrophenol using biogenic gold and silver nanoparticles derived from Breynia rhamnoides. Langmuir 27: 15268-15274.

34. Majumdar R, Bag BG, Maity N (2013) Acacia nilotica (Babool) leaf extract mediated size-controlled rapid synthesis of gold nanoparticles and study of its catalytic activity. Int Nano Lett 3: 53.

35. Dasgupta S, Banerjee K, Patil SH, Ghaste MS, Dhumal KN, Adsule PG (2010) Optimization and comparison of one- and two dimensional gas chromatography time-of-flight mass spectrometry for separation and estimation of the residues of 160 pesticides and 25 persistent organic pollutants in grape and wine. J Chromatogr A 1217: 3881-3889.

36. Banerjee K, Utture S, Dasgupta S, Pradhan S, Kandaswamy C (2012) Multiresidue determination of 375 organic contaminants including pesticides, polychlorinated biphenyls and polyaromatic hydrocarbons in fruits and vegetables by gas chromatography-triple quadrupole mass spectrometry with introduction of semi-quantification approach. J Chromatogr A 1270: 283-295. 